\title{
Professor Bork on Vertical Price Fixing:
}

\section{A Rejoinder}

\author{
J. R. Gould $\dagger$ and B. S. Yamey*
}

Professor Bork's Reply ${ }^{1}$ to our earlier Note ${ }^{2}$ on his original Article ${ }^{\mathfrak{3}}$ raises a number of new issues and reveals some misunderstanding of what we set out to do in our paper. In this Rejoinder we shall address ourselves to the new issues raised and shall clarify our position. The discussion follows the sequence of our earlier paper and of Bork's Reply. But first two general matters require attention.

First, Bork writes as though we put forward a specific policy recommendation concerning resale price maintenance (r.p.m.) (references to which in this Rejoinder, unless otherwise qualified, are to r.p.m. in the absence of manufacturer and reseller cartels). Thus he says we "recommend a rule against all r.p.m. because r.p.m. may restrict output."4 The reader will not find such a policy prescription (or, indeed, any policy prescription) in our paper, which was concerned primarily with the reasoning behind Bork's policy recommendations. In the introduction to our Note we said that we found Bork's thesis interesting because it claimed that in a wide class of cases r.p.m. could not fail to benefit consumers. If this contention were true, it would have important implications for public policy: courts or other agencies could be spared the task of evaluating, case by case, the economic effects of the practice, and would instead have to decide only whether in the particular case r.p.m. was an instrument of a cartel.

Wide generalizations with important implications are to be welcomed in any science-if they are true. The predominant purpose of our Note was to refute Bork's generalization. In a short Note devoted mainly to refuting his proposition we did not feel called upon to present an empirical evaluation of the gains and losses of an anti-r.p.m. policy (as Bork suggested we ought to have done). ${ }^{\cdot}$ Bork had attempted

$\dagger$ Professor of Economics, London School of Economics and Political Science.

- Professor of Economics, London School of Economics and Political Science.

1. Bork, A Reply to Professors Gould and Yamey, 76 YALE L.J. 731 (1967).

2. Gould \& Yamey, Professor Bork on Vertical Price Fixing, 76 YALE L.J. 722 (1967).

3. Bork, The Rule of Reason and the Per Se Concept: Price Fixing and Market Di. vision II, 75 YALE L.J. 373 (1966).

4. Bork, supra note 1 , at 742 .

5. Bork displays a complete misunderstanding of the scope and purpose of our Note when he says (id. 732):

Since Gould and Yamey think ... r.p.m. ... may either increase or decrease output, 
to close a large area of the debate on r.p.m.--our concern was to show that he had failed to do so.

In this Note we shall therefore not deal with those points raised in Bork's Reply which stem from his erroneous attribution of a definite policy prescription to our paper. Bork's misunderstanding may have arisen from our statement that certain specified considerations "set up a presumption that r.p.m. is against the interests of consumers." $\mathrm{He}$ may have thought that we had in mind an irrebuttable presumption. We did not; if we had had this in mind, we would have said so.

The second general point has serious consequences for Bork's position. At several places in his Reply, Bork deals with certain of our arguments by counter-arguing, in effect, that if the situations postulated by us were to occur, they would not persist because of actions which it would be profitable for some manufacturer(s) or reseller(s) (including new firms) to take. It is necessary for Bork to assume that there are no barriers to the entry of new firms, and that consumers (or enough of them) would be largely indifferent as between the established price-maintained brands and new brands introduced by new or existing firms. In other words, Bork assumes that new competition would protect consumers against the actions of manufacturers who restricted output, intentionally or otherwise, by practicing r.p.m.

We agree that where entry is easy and where brand preferences are weak there is little danger that r.p.m. could operate against the interests of consumers. But these conditions do not prevail in all markets. Nor does Bork himself seem to believe that these conditions apply generally. For if he did hold such a view, he would not have found it necessary, as he does, to distinguish in his policy prescriptions between cartel-organized r.p.m. and r.p.m. by individual manufacturers in the absence of cartel arrangements. ${ }^{7}$ Entry of new firms and new brands would counteract output restrictions whether practised by cartels or by firms individually. Indeed, there would be no need for any antitrust or monopoly policy whatsoever if no firm or collection of firms had power to affect output and prices, or if such power was negligible or ephemeral because of the ease with which new firms could establish themselves as competitors.

their first task should be to ask whether these varieties can be segregated and handled differently at an enforcement cost which is justified by the benefits. If not, their second task should be to estimate whether on balance consumers would be benefited by outlawing all manufacturer-desired r.p.m. or none. [They] ... do not appear to have built this bridge between their objections to my thesis and their suggested public

policy.

6. Gould \& Yamey, supra note 2, at 730.

7. Bork, supra note 3, esp. at 474-75. 


\section{I.}

In the first section of our Note we presented four counter-examples (with a fifth in footnote 6) to refute Bork's thesis that r.p.m. is necessarily output-increasing. Bork takes issue with each of these.

His discussion of our first counter-example calls for the longest comment. We postulated a situation in which a manufacturer of the branded good could increase the demand for it either by r.p.m. or by an advertising campaign. We showed that r.p.m. could be the more profitable of the two courses even when the number of units sold was smaller than with the alternative course of action and concluded that r.p.m. could lead to a reduction in output. Bork says our analysis is fallacious and also that in any case "output" has not been reduced in the postulated circumstances. We deal with these two points in reverse order.

Notwithstanding his objection to our counter-example, Bork nevertheless concedes in his Reply that r.p.m. may reduce sales (presumably, that is, number of units sold) as compared with other methods of distribution. But this retreat is swiftly followed by a counter-attack:

It does not follow, however, that output is lower or prices higher. The composition of the product has changed. . . . But if the new product proves more profitable it means that consumers prefer the new allocation of resources. That in turn means the output of the economy has increased. 8

We must say at once that our counter-examples assumed that "output" in Bork's original article meant number of units of the product sold-we believe that many readers must have put the same interpretation on the word. But even if "output" refers to the "output of the economy," we are at a loss to know from where Bork derives the proposition quoted in the preceding paragraph. No one, so far as we are aware, has demonstrated rigorously that promotional activities which increase a manufacturer's profit necessarily lead to an improvement in the allocation of resources. Certainly Bork's argument, or rather assertion, does not attain the necessary standards of rigor.

There are, indeed, good reasons why students of welfare theory have been able to say so little about the welfare effects of promotional activity. Such activities involve attempts to induce the consumer to change his preferences and tastes. Students of welfare economics have, however, generally been forced to confine their analyses to examination of

8. Bork, supra note 1 , at 733-34. 
the effects of such things as different taxes, industrial structures or trade practices on consumers with given tastes. This is because it is felt permissible to say that if a consumer with given tastes prefers one collection of goods which is not available to him to another which is, his welfare is increased if the change under consideration enables him to have the former rather than the latter. When tastes can be assumed to remain constant we have a stable yardstick against which to appraise alternatives. But if, for example, the trade practice not only changes the collections of goods available to the consumer, but also simultaneously changes the consumer's ranking of those collections, we have no such stable yardstick with which to appraise the effects. ${ }^{9}$

We do not mean to suggest that it is in principle impossible to discuss the welfare effects of promotional activities. Rather, our purpose in the foregoing discussion has been to show why, in terms of standard welfare economic analysis, little can be said about their effects, and, in particular, why we believe the proposition that promotional activities which are profitable to the entrepreneur necessarily improve the allocation of resources has not, and indeed probably cannot, be derived from standard welfare economics. Bork relies on standard welfare economics; and he has not demonstrated the validity of his proposition. ${ }^{10}$

We turn now to Bork's criticism of our analysis in the first counterexample. We postulated an advertising campaign the costs of which are a fixed cost for the purpose of output determination because they do not enter the relevant marginal cost schedule or curve. Bork says the advertising costs are "clearly classifiable as marginal" because the "manufacturer hypothesized by Gould and Yamey is certainly not faced with a stated and invariable expense for his advertising."11 His argument that the costs should be classified as marginal costs is misconceived. It is true that the costs of different kinds and intensities of advertising campaigns vary, as do their probable effects on the demand for the advertised

9. Similar difficulties arise with promotional activities that involve no more than the use of resources to provide information to consumers. For example, can we have the same ranking function to compare two situations when one of them includes goods which the consumer previously did not know about?

10. Bork's reliance on standard welfare economics is evident from his statement that a cartel entails misallocation of resources insofar as it "creates or increases a divergence between price and marginal cost. ..." Bork, supra note I, at 734 n.4. At this juncture we need point out only that Bork does not (and, we believe, cannot) demonstrate that profitable promotional activity cannot increase the gap between price and marginal cost (as compared with the gap in the alternative situation without the particular promotional activity). Furthermore, while our first counter-example is so specified that the divergence of price from marginal cost is lower with r.p.m. than vithout it, the opposite is true of the counter-example outlined in our footnote 6 (Gould \&: Yamcy, supra note 2, at 724 n.5) and of the other counter-examples also.

11. Bork, supra note 1, at 733 . 
product. Comparison ex ante of the costs and returns for the various campaigns contemplated is necessary for deciding which campaign is likely to be the most profitable. But our problem was to compare the profit-maximising outputs associated with the two alternative strategies, an adverstising campaign and r.p.m. For this purpose it is proper to assume that the best advertising campaign has been selected, and to derive the profit-maximising output, taking the advertising expenditure as given. Now the relevant data for output determination are variations in revenue (marginal revenue) and variations in costs (marginal costs) with respect to changes in output. Clearly, in this context the advertising expenditure on the chosen campaign is a fixed cost because it does not vary with output and does not affect the marginal cost curve.

Similarly, when we consider the r.p.m. strategy it is proper to assume that the best retail margin has been selected. However, now when we analyse the profit-maximising output, the increment in the retail margin (as against the competitive retail margin) must be added to the marginal cost curve (or, equivalently, deducted from the marginal revenue curve).

The reason for conducting the analysis in this way is that, having hypothesized that each of the two strategies has the same effect on the demand curve, we are in a position to compare their profit-maximising outputs. The marginal revenue and marginal costs of production are the same for both strategies; r.p.m. raises the marginal cost curve but the postulated advertising does not; therefore r.p.m. will result in the smaller output, although it may well be the more profitable strategy.

Bork misconceives the nature and purpose of the distinction between fixed and variable costs when he says advertising is not a fixed cost because the manufacturer is not faced with a "stated and invariable expense." The costs of buildings or plant are a matter of choice at the planning stage, yet they are fixed costs for the purpose of output deter"* mination once the buildings or plant has been chosen. Similarly, in our example, advertising costs are fixed with respect to output. ${ }^{12}$

Bork's comments ${ }^{13}$ on our second and third counter-examples do not

12. It is not difficult to think of types of advertising outlays which are not fixed costs for purposes of price determination. Some outlays vary with output, for example where advertising material is included on or in each packet of the product. But the fact that another type of advertising outlay does not give rise to a fixed cost does not, of course, invalidate our counter-example.

It was in the interests of simplified exposition that advertising was assumed to be th fixed cost in our example. The particular result, however, does not depend upon this assumption. The example could be modified to accommodate the situation in which the most profitable advertising program had both fixed and variable cost elements, and yct would give the same result.

13. Bork, supra note I, at 734-37. 
require a detailed reply from us. They rely heavily on the assumption that the entry of new firms and the acceptance by consumers of new brands occur without any difficulty, and this assumption has already been examined. All we need add specifically is that in our third counterexample the key point is that a larger reseller is generally more easily able to promote a new brand than is a smaller reseller. We do assume, as Bork rightly says, ${ }^{14}$ the possibility of entry: but this is not the same thing as saying that entry is easy and that the established manufacturer has no room for maneuver.

Our fourth counter-example refers to the use of r.p.m. to remove one source of instability in the market shares of oligopolist manufacturers - the instability that derives not from any action of the manufacturers but from the price competition of resellers. Bork counters by pointing out that since r.p.m. will encourage resellers' competition in the form of the supply of services, instability will persist. Two points are in order. First, reseller competition in supplying consumer services changes consumers' shopping behavior vastly more slowly than price competition. It therefore disturbs market shares of rival brands less than does price competition. This applies not only to the long run but also, and even more so, to the short run; and the instability referred to in our counter-example is primarily short-run instability. That service competition is less disturbing and acts far more slowly than price competition has been well recognized by retailer supporters of r.p.m. (and, indeed, by participants in all kinds of collective arrangements to restrain price competition). Second, if reseller competition is channelled into services in a situation where each reseller typically sells a number of rival brands within the same product-group, the gains in sales of the successful resellers and the losses of the unsuccessful will tend to be spread unselectively over all brands, and to that extent brand market shares will be left largely undisturbed. In contrast, if reseller competition is allowed to take the form of price competition, it is unlikely that any reseller in adjusting his prices to increase total sales will so contrive matters that his proportionate sales of each brand remain unchanged. Moreover, should the initiator of a particular bout of price competition favor the sales of one brand, the competitive responses of affected resellers might well serve to favor its sales still further. In short, while we agree that r.p.m. does not eliminate all instability originating at the reseller level, we contend that r.p.m. reduces the degree of instability. (Bork's further point that r.p.m. is an expensive way of achieving this

14. Id. 735 . 
particular objective applies equally to other objectives, such as increasing the number of outlets or increasing "output" in any other way. The fact that r.p.m. has a cost is important; it does not mean, however, that therefore its use cannot be profitable.)

Bork argues further that our fourth counter-example contradicts our expressed agreement with him that r.p.m. is unlikely to be valuable as an aid in the policing of a manufacturers' cartel arrangement. We do not think we have been inconsistent, since we understood "policing" to mean the detection of secret price-cutting by manufacturers. If "policing" is to cover anything that contributes towards the maintenance of an effective manufacturers' agreement or noncollusive "understand. ing" about prices, then we withdraw our earlier expression of acceptance of Bork's view.

Bork concludes Section I of his Reply by saying that our counterexamples "do not . . . withstand analysis."15 We conclude, on the contrary, that they survive the battery of criticism which Bork has directed at them.

\section{II.}

Professor Bork begins Section II of his Reply by saying that we advanced "four arguments to support the propriety of judicial supervision of r.p.m. even where it is practiced with the purpose of creating effciency." 16 Bork, however, is mistaken. We were concerned with his particular argument (largely by way of analogy) in support of his proposition that judicial supervision should not be allowed. Judicial supervision may be unwise or inexpedient even if, as we suggested, Bork's particular argument is incorrect. In the discussion we also considered related policy issues ignored or neglected by Bork. But even if we had advocated judicial supervision of r.p.m. (i.e., that the courts be required to "ratify or reject" r.p.m. in particular cases), this would not have warranted the inference that it "would turn the antitrust laws into a mandate for the judiciary, of all inconceivable institutions, to manage the now private sector of the economy." 17 We pointed out that management decisions to have r.p.m. (and similar restrictive practices) differ from management decisions concerning, say, investment and inventory

15. Id. 738.

16. Id. Bork fails to notice that he attributes to us two contradictory policy prescriptions-we are supposed to have recommended the complete abolition of r.p.m., and also the judicial control of the use of r.p.m.

17. Id. 739. 
levels precisely because the former directly restrain reseller competition and affect other firms' freedom of decision, while the latter do not have these implications. The false analogy between the two types of decisions has continued to mislead Bork.

We do not think it fruitful to explore further the propriety of judicial supervision. Instead, we move on to a different but related matter. We called attention to the apparent inconsistency in Bork's position in that he opposes the supervision of manufacturers' marketing policies by the judiciary but supports r.p.m. which amounts to the supervision of resellers' price policies by manufacturers. Bork's justification of the latter position is that the manufacturer may see advantages for himself in a particular form of distribution which may not be best for all resellers. He concludes that the interests of each reseller are "parochial" and that the manufacturer's "more general judgment should prevail."18 Bork's policy conclusion requires the premise that the manufacturer will adopt r.p.m. if, and only if, it serves to increase "output" and thereby to promote economic welfare. This premise we have already discussed above; but since it is central to Bork's thesis, we do not think it is superfluous to take another look at it, but from a different angle. The discussion that follows bears on Bork's "general" vs. "parochial" dichotomy and introduces a consideration not specifically taken into account in Section I of our previous paper nor in Section I of the present paper.

It is implicit in Bork's analysis that the manufacturer considers all the favorable and unfavorable effects on the welfare of consumers of his decision for r.p.m. because these effects have correspondingly favorable or unfavorable effects on his profits. If the increase in consumer welfare exceeds the reduction in consumer welfare (the latter due to the inability of each reseller to adjust optimally to the situation of his

18. Id. As regards the question of the knowledge possessed by the manufacturer and and resellers, respectively, we merely wish to draw attention to the prima facic presumption-which forms part of the traditional case for a private-enterprise economy-that the independent entrepreneur knows more about his own resources and his "local" circum. stances and opportunities than anyone else. The overriding of his decisions by some other entrepreneur must involve a "loss" to the economy of the value of some relevant information, itself a scarce resource.

The argument used by Bork that r.p.m. does no more than the manufacturer could do by vertical integration into the reselling trade is inappropriate. The vertically integrated manufacturer-reseller is an entrepreneur in manufacturing and also in reelling; and the prima facie presumption in favor of the wisdom of his decisions pertains to each of the two activities. The same does not apply in respect of reselling in the case of the nonintegrated manufacturer who practices r.p.m.

It may be noted also that the consideration discussed in the text (p. 942 supra) does not apply to the vertically integrated manufacturer-reseller to the extent that his policies in marketing his manufactured goods adversely affect his sales, as receller, of other goods. Some, at least, of the effects which are external to (and hence ignored by) the nonintegrated manufacturer are internal to the vertically integrated manufacturer-reseller. 
"parochial" consumers), then, it is implied, the manufacturer's profits will be greater, and conversely.

This reasoning, however, is erroneous insofar as it relies on a coincidence of the interests of the individual manufacturer and of those of consumers of goods in general. The manufacturer is concerned only with his gains and losses from r.p.m. He is not concerned, for example, with welfare losses to consumers arising from the effect of his r.p.m. decision on the terms on which other goods are offered by resellers, since these losses do not affect his profits (except to the limited extent that they may in turn affect the sales of his goods). In this sense the manufacturer's interests are "parochial." Bork's general proposition is invalid if the adverse welfare effects caused by the manufacturer but not reflected in his profits are admitted into the analysis.

Such effects could be ignored-as they would be zero-if each reseller handled only the goods of the manufacturer in question and nothing else. Resellers, however, typically sell a range of goods and brands from a number of suppliers. Consumers' demands for resellers' offerings are interdependent, and the resellers' costs of supplying individual goods are also interdependent. The inability of a reseller to offer a brand at a competitively attractive price may adversely affect his business as a whole and hence the terms on which he supplies other goods. It may reduce the number of consumers he can attract and the volume of his business and increase the costs of his operations. It may also affect his rate of growth, with adverse effects on his future costs and the prices he charges for other goods. Of course, r.p.m. in respect of an unimportant brand is unlikely to have much, if anything, in the way of these side effects. The likelihood of substantial adverse side effects increases with the importance and with the number of brands subject to r.p.m. and, even more, with the pervasiveness of r.p.m. generally in relation to the ranges of goods which can profitably be offered together by resellers. These effects, which are side effects from the individual manufacturer's point of view, are among those which students of r.p.m. consider when they examine the effects of the practice on the organization and performance of the distributive trades. ${ }^{10}$

19. In the discussion above we have referred only to the adverse side.cffects of r.p.m. which would not enter into the individual manufacturer's calculations. There may be favorable side-effects, which similarly would not enter into these calculations. For example, for some resellers the optimal adjustment to r.p.m. might include the reduction of the prices of some other goods. Such favorable side-effects would almost certainly not outweigh the unfavorable. (According to Bork, supra note 1 , at 731 , the price-maintaining manufacturer gives the reseller an additional margin in order to buy from him "iricreased activity" such as promotional activity, presumably in respect of the manufacturer's own brands. To the extent that resellers use the additional margin to cut prices of other goods or to provide services in respect of other goods, the manufacturer derives less benefit from 
We conclude this Section with an apology to Professor Bork and the reader for a mistake in the concluding paragraph of Section II of our earlier paper. ${ }^{20}$ We perpetrated a non sequitur by saying, inexcusably, that because some manufacturers have wrongly predicted the effect on their sales of the removal of r.p.m., therefore all manufacturers generally have been wrong. A weaker conclusion should properly have followed. This does not, however, destroy our argument, which requires no more than that some manufacturers have been mistaken and others are likely to be mistaken. We may point out, also, that Bork's reference to businessmen who would like to repeat their "mistake" of having r.p.m. does not prove that their motivation is the promotion of "efficiency": the analysis in our original Section I demonstrates that there are other motivations.

III.

We turn now to the relation between criteria for economic policy and theoretical welfare economics. First, we must distinguish two areas in which the criteria are to apply: (I) in the formulation of antitrust policy; and (2) in supplying the courts (or other implementing agency) with operational rules.

With regard to (2), we are all for as much simplicity and clarity as possible. Bork misunderstands our position when he says that we criticised his criterion-the effect on output-for being "too simple."11 If there had to be rules, we would prefer rules to be of the kind "consider whether output in this industry will be increased by r.p.m." rather than of the kind "consider whether resource allocation in the economy as a whole would be improved by r.p.m. in this industry." However, since Bork's main thesis is the legitimacy of r.p.m. in the absence of cartels, he is concerned with rules of type (2) only in requiring the courts to determine whether cartelization is present.

Bork's main concern is with criteria of type (1). In advocating policy one must, of necessity, make do with what theoretical and empirical knowledge is available. We may bemoan our incomplete knowledge, but we shall wait forever if we wait on complete knowledge before tackling practical questions. We have no objection to someone's setting

his r.p.m.) For our purposes it is enough that it is possible, and sometimes virtually certain, that the net adverse side-effects on "welfare" outweigh the postulated increase in "efficiency" created by r.p.m.

20. Gould \& Yamey, supra note 2, at 728.

21. Bork, supra note 1 , at 740 . 
up simplified criteria, provided he attempts to justify them on the basis of available knowledge and also, from the same source, points out the shortcomings. Our criticism was that Bork essayed the first (although unsuccessfully), but not the second.

We cannot help but feel that Bork's discussion of his criterion is obscure, not only to ourselves, but also to many other readers. As we said above, in our original Note we assumed that Bork's simplified criterion was "effects on output" (in the straightforward sense of number of units sold by the firm) and that he had attempted to justify this criterion in terms of the general-equilibrium welfare economics theo. rems of resource allocation. We suggested that this justification was erroneous. We should explain that although Bork's "output" criterion is ill-founded in general-equilibrium theory, we did not for that reason judge it to be a bad criterion if "output" referred to the output of the particular activity and not to that of the economy as a whole. Indeed, we have rather more sympathy for this type of approach, which is related to the appraisal of effects of r.p.m. in a particular case on the consumers immediately affected, rather than one which attempts to evaluate its effects on the economy as a whole.

It is now clear, especially from footnote 4 in Bork's Reply, that he rests his case directly on general equilibrium theory. We can paraphrase his position in the following way: "A trade practice is judged harmful if it reduces the output of the whole economy. Practices which increase the divergence between price and marginal cost reduce the output of the economy." Bork's main contention then becomes: "R.p.m. always decreases (or else leaves unchanged) the divergence between price and marginal cost." He does not establish this last proposition. The nearest he gets to a justification is to assert that since some manufacturers find r.p.m. an "efficient," i.e., a profitable, means of distribution, it must increase the output of the economy. In fact there is no obvious reason to suppose that r.p.m. entails a narrowing of the gap between price and marginal cost: the practice may affect the manufacturer's rate of output, the demand for the good and the marginal costs of the manufacturer and of resellers, and it is possible to conceive of cases in which the practice increases, and cases in which it decreases, the divergence between price and marginal cost.

Even had Bork succeeded in establishing his proposition, the restrictive assumptions underpinning the resource-allocation theorems relating price and marginal cost should be made clear before policy conclusions are derived. Bork is right in suggesting that behind our admittedly somewhat cryptic remarks, we had in mind such considera- 
tions as effects on the distribution of income and the theory of second best. In addition, we had in mind that these theorems are derived from static equilibrium theory (and do not apply, for example, to situations in which technical knowledge and consumer preferences are not static), that the "static" considerations should be supplemented by "dynamic" considerations such as the effect on innovation mentioned by us in our Note, and that externalities introduced complications. We refrained from detailed discussion of the implications of income distribution and the theory of second best; but since Bork has put the matter at issue in his Reply, we take the opportunity to comment on his discussion.

Bork's treatment of the topic of income distribution is peculiar. He suggests that antitrust law and the courts could not deal with effects on the distribution of income because this would require tracing the effects of a practice throughout the whole economy. We think lawyers will appreciate that a substantial part of the law concerns itself precisely with the question of income distribution. For example, the concept of "damages" is concerned with the losses a wronged party has suffered. The courts are familiar with, and expert at, this kind of problem. Moreover, we would suggest that a major consideration in the minds of policy-makers over the centuries has been that monopoly and restrictive practices enriched the supplier at the expense of his customers. Antitrust policy-makers can, should and do concern themselves with income distribution, although as a practical matter they, and the courts, do not concern themselves with every last ripple of effect on incomes in every part of the economy. We agree that decisions about the pattern of income distribution are policy decisions properly within the province of the legislature. But the instruments which legislatures use to implement their decisions are not only taxes and subsidies, but also laws concerning practices, including restrictive practices, which affect the distribution of income.

We come now to the theorems of resource allocation, and in particular to the implications for them of the theory of second best. A central theorem of welfare economics is that if the whole economy is composed of perfectly competitive industries (and given certain other conditions which are not relevant to the present discussion), the necessary and sufficient conditions for a welfare maximum are met. From this result it is tempting to conclude that if we have an economy which is perfectly competitive except for two industries which are monopolized, we necessarily shall increase welfare by inducing one of the

22. And indeed criminal practioes such as theft and forgery. 
monopolists to produce at the competitive level of output. But this conclusion is false, since although we have equalized values of marginal products as between the first monopolist and the competitive industries, the factors required for this expansion of output may well have come from the second monopolist, where the values of their marginal products may have been higher. More generally, according to the theory of second best, if we cannot remove all divergencies from perfect competition, we cannot say that removing some of them will necessarily increase welfare.

Bork says in his Reply that in order to apply the theory of second best a court would need to have a vast amount of empirical information about the economy (and, we might add, a vast computational ability). This task, he believes, the courts could not perform. We do not disagree. What Bork fails to realize, however, are the consequences of the theory of second best for the theorems on which he believes his criterion is based. We have already shown that Bork has not established that profitable r.p.m. necessarily will narrow the discrepancy between price and marginal cost. The theory of second best tells us that even if Bork had established or could establish that the discrepancy would necessarily be reduced, we would be none the wiser: in terms of welfare economics we would still not know the direction in which welfare had changed as a result of the postulated narrowing of the discrepancy.

The theory of second best has important implications for economic policy-for if we acknowledge that we live in a world where all elements of monopoly power cannot possibly be eradicated (and govern. ment intervention through taxes and subsidies has the same kind of effect), we must also acknowledge that simple rules, such as that price should equal marginal cost, do not have secure theoretical underpinnings in welfare economics. Indeed, the present state of welfare economics is such that it is extremely doubtful whether there are any general and simple rules deducible from welfare economics which provide practical help for economic policy insofar as economic policy is concerned with optimal resource allocation throughout the economy.

In summary, our views on the theoretical foundations for economic policy, in particular as related to antitrust, differ greatly from Bork's. We think policy-makers should concern themselves, among other things, with the effects of, say, restrictive practices on income distribution. We believe, further, that the resource-allocation theorems of neoclassical welfare economics offer no secure foundation for policy and certainly cannot serve as its basis. We believe, however, that there are some simpler and more familiar arguments which support a pre. 
sumption against restraints on competition-for example, that competition is a spur to efficiency in the use of resources within firms and industries, that competition promotes experiment and innovation, and that restraints on competition tend to raise prices and to restrict consumer choice. There is no doubt a variety of ways in which the presumption may be given effect in the form of specific policy measures, with a variety of roles for the courts to play. But it is not, and was not, our purpose to go into these wider issues. 